\title{
Multipotential stromal cell abundance in cellular bone allograft: comparison with fresh age-matched iliac crest bone and bone marrow aspirate
}

\begin{abstract}
Aim: To enumerate and characterize multipotential stromal cells (MSCs) in a cellular bone allograft and compare with fresh age-matched iliac crest bone and bone marrow (BM) aspirate. Materials \& methods: MSC characterization used functional assays, confocal/scanning electron microscopy and whole-genome microarrays. Resident MSCs were enumerated by flow cytometry following enzymatic extraction. Results: Allograft material contained live osteocytes and proliferative bonelining cells defined as MSCs by phenotypic and functional capacities. Without cultivation/expansion, the allograft displayed an 'osteoinductive' molecular signature and the presence of $\mathrm{CD} 45-\mathrm{CD} 271+\mathrm{CD} 73+\mathrm{CD} 90+\mathrm{CD} 105+\mathrm{MSC}$; with a purity over 100 -fold that of iliac crest bone. In comparison with BM, MSC numbers enzymatically released from $1 \mathrm{~g}$ of cellular allograft were equivalent to approximately $45 \mathrm{ml}$ of BM aspirate. Conclusion: Cellular allograft bone represents a unique nonimmune material rich in MSCs and osteocytes. This osteoinductive graft represents an attractive alternative to autograft bone or composite/synthetic grafts in orthopedics and broader regenerative medicine settings.
\end{abstract}

Keywords: bone marrow $\bullet$ cellular allograft $\bullet$ multipotential stromal cells $\bullet$ osteocytes concerns due to potential increased risks of adverse events including inflammation and possible new malignancy $[7,8]$, while synthetic calcium phosphate grafts can only provide the osteoconductive scaffolding component. Local (BM) aspirate injections on the other hand, typically have low osteogenic cell yields and poor cellular attachment to scaffolds, which may lead to only a few osteogenic cells remaining at the intended site of repair [9]. As a result, new developments have emerged such as so called 'composite' or 'hybrid' grafts [10] that compose of either a synthetic scaffold [11-13] or an allograft [14] intraoperatively 'loaded' with autologous BM aspirate or volume-reduced BM 'concentrate'.

In general, the use of allografts in bone repair have been impeded by perceived safety concerns with regards to disease transmission and lack of osteogenic properties similar to synthetics [15]. However, improved allograft safety has now been achieved through
Thomas G Baboola|,1, Sally A Boxall ${ }^{\ddagger 1}$, Yasser M El-Sherbiny', Timothy A Moseley², Richard J Cuthbert ${ }^{1}$, Peter V Giannoudis' ${ }^{1}$, Dennis McGonagle ${ }^{1}$ \& Elena Jones ${ }^{*, 1}$ 'Leeds Institute of Rheumatic \& Musculoskeletal Medicine, Room 5.24 Clinical Sciences Building, University of Leeds, Leeds, LS9 7TF, UK

${ }^{2}$ NuVasive, Inc., Biologics R\&D, San Diego, CA, USA

*Author for correspondence:

Tel.: +441132065647 msjej@leeds.ac.uk

${ }^{\ddagger}$ Authors contributed equally
Future
Medicine $\mathrm{fs}$ par of 
advanced donor screening and the use of highly sensitive viral nucleic acid testing [15]. The lack of osteogeneic cells in typical allograft, on the other hand, has always resulted from the 'harsh' tissue processing necessary to completely remove the donor cells creating an acellular material. However, in the last 10 years the concept of a 'viable' cellular bone allograft has emerged, which incorporates the selective removal of the immune cell component from the graft, while preserving the osteogenic, nonimmune cells. In fact, the first such material, Osteoce ${ }^{\circledR}$, has been used clinically since 2005 for bone regeneration for spine, maxillofacial and long-bone applications [16-20], with successful outcomes and no graft-associated adverse events recorded. Osteocel graft material is obtained from cadaveric cancellous bone, in which selective cell preservation is achieved by tissue processing and washing, with the addition of demineralized cortical bone before the combination is cryopreserved.

Very little has been published about the relative number and vitality of osteogenic cells remaining on 'viable' cellular allografts post-cryopreservation. A limited number of studies published to date have demonstrated the presence of osteogenic multipotential stromal cells (MSCs) in Osteocel; however, this was achieved only following extensive cellular cultivation and expansion [20,21]. The aim of this study was therefore to document, enumerate and phenotypically characterize MSCs in this cellular allograft material without culture expansion (as would be seen clinically). We also investigated and compared the abundance of native MSCs in the cellular allograft with that of 'gold-standard' freshly obtained IC bone graft and BM aspirate.

\section{Materials \& methods}

\section{Patient samples}

A total of 16 different Osteocel lots (NuVasive, Inc., CA, USA) were analyzed. Each lot was from a different tissue donor: ten for flow cytometry, tissue culture, confocal and scanning electron microscopy ( 1 and $2 \mathrm{~cm}^{3}$, median donor age 35 years, range $23-41$ years) and six for whole-genome microarray $\left(5 \mathrm{~cm}^{3}\right.$, median donor age 31 years, range 24-39 years). Control samples included age-matched BM aspirate and IC bone; additionally, cancellous bone from excised femoral heads was used for method optimization of flow cytometry ( $\mathrm{n}=6$ donors).

BM aspirates were carefully drawn from the IC of acute trauma patients or patients undergoing elective orthopedic surgery for metalwork removal $(\mathrm{n}=16$, median age 34, range 24-40). For BM aspiration, consistency was assured in terms of surgeon (same person for all samples), aspirate location (anterior IC), needle (Stryker 306-111, 11-gauge, bevel tipped trocar, MI, USA), volume of aspirate $(20 \mathrm{ml})$ and draw method (single $20 \mathrm{ml}$ draw). Control IC cancellous bone samples (average weight $0.2 \mathrm{~g}$ ) were collected from the IC of trauma patients undergoing pelvic reconstruction $(\mathrm{n}=14$ donors, median age 40 years, range 23-48). All patients had no underlying disease. The sample collection protocols were approved by National Research Ethics committee.

\section{Osteocel sample processing for explant \& microscopy studies}

Osteocel allograft consists of 'viable' cancellous bone fragments and acellular/nonviable demineralized bone matrix (DBM) particles (DBM processed from cortical bone of the same donor). Osteocel samples were thawed in accordance with manufacturer's instructions in a $37^{\circ} \mathrm{C}$ water bath and washed with $10 \mathrm{ml}$ of phosphate buffered saline (PBS, Invitrogen, Paisley, UK). The larger cancellous bone fragments were separated from smaller DBM particles using a sterile $850-\mu \mathrm{m}$ metal sieve (Fisher, Loughborough, UK). Subsequently, cancellous bone fragments were transferred into $100 \mathrm{~mm}$ culture dish and washed with $10 \mathrm{ml}$ of PBS. Explant cultures were initiated by replacing PBS with $15 \mathrm{ml}$ of nonhematopoietic expansion medium (Miltenyi Biotec, Bisley, UK). Dishes were fed twice-weekly with half-media changes until reaching confluence (termed passage $0[\mathrm{p} 0]$ ); subsequently, cells were detached using $0.05 \%$ trypsin-EDTA (Invitrogen), re-seeded at a density of $10^{4}$ cells $/ \mathrm{cm}^{2}$ and further expanded for two passages for functional assays and flow cytometry analysis.

In all the remaining experiments, cancellous bone fragments were analyzed immediately following separation from DBM particles (termed Day 0 Osteocel), by flow cytometry, confocal or environmental scanning electron microscopy (ESEM) and histology. Samples intended for ESEM were fixed (3.7\% formalin/PBS) and stored at room temperature in PBS until use. Confocal microscopy was used for the detection of viable and nonviable cells by staining nonfixed samples with the live/dead viability stains Calcein AM and ethidium homodimer-1 (Invitrogen), according to manufacturer recommendations. Images were taken of hydrated samples using a $20 \times$ water dipping objective. Optical sections were made $3 \mu \mathrm{m}$ apart using a Leica SP2 TCS laser scanning microscope (Leica, Buckinghamshire, UK); the bone surface was imaged using reflected light (excitation at $488 \mathrm{~nm}$ and emission between 479-498 nm). ESEM was used to visualize cell coverage and subsequent cell growth on scaffold surface and was performed on hydrated samples using a Hitachi S-3700N variable pressure scanning electron 
microscope (Hitachi, Berkshire, UK), as previously described [22]. Histology slides were prepared following routine demineralization with formic acid. Hematoxylin and eosin staining was performed on $5 \mu \mathrm{m}$ sections using standard histology protocols.

\section{Osteocel sample processing for flow cytometry} to detect \& quantify native MSCs

To enumerate and characterize MSCs in Day 0 Osteocel, we used the CD271 marker that is specific for uncultured intra-osseous MSCs [23-28], in combination with CD45 as a negative marker. Bone fragments were weighed, washed thoroughly with PBS, placed in $0.5 \mathrm{ml} 0.25 \%$ collagenase (Stem Cell Technologies, Grenoble, France) per $0.2 \mathrm{~g}$ of tissue and digested for $4 \mathrm{~h}$ with gentle agitation to obtain single-cell suspensions [27]. The fragments were weighed in order to calculate the total number of MSCs per gram of bone. The liquid fraction containing cells was filtered through a $70 \mu \mathrm{m}$ filter (BD Biosciences, Oxford, $\mathrm{UK})$, centrifuged $(400 \times g, 5 \mathrm{~min})$, washed in PBS and diluted in FACS buffer (PBS, $0.5 \%$ bovine serum albumin and $2 \mathrm{mM}$ EDTA) to give a final staining volume of $200 \mu \mathrm{l}$. Nonspecific binding was blocked using $10 \mu \mathrm{l}$ FCR blocking reagent (Miltenyi Biotec) and incubated for $10 \mathrm{~min}$ before staining with CD90FITC, CD105-PE (both from Serotec, Kidlington, UK), CD73-PerCP-Cy5.5, CD45-PE-Cy7 (both from BD Biosciences), CD271-APC (Miltenyi Biotec), aqua fluorescent dye and Calcein AM from the live/dead violet viability/vitality kit (Invitrogen), all at manufacturer's recommended concentrations. CD73, CD90 and CD105 were used to confirm the MSC identity of CD $455^{-} \mathrm{CD} 271^{+}$cells in compliance with the International Society of Cell Therapy (ISCT) criteria for MSCs [29]. Cells were incubated for $30 \mathrm{~min}$ on ice in the dark before adding $50 \mu \mathrm{l}$ of thoroughly mixed CountBright beads (Molecular Probes/Life Technologies, Paisley, UK) to permit absolute cell quantification. The sample volume was made up to $400 \mu \mathrm{l}$ with FACS buffer before analyzing on an LSRII flow cytometer using FACSDiva ${ }^{\mathrm{TM}} 7$ software (Beckton Dickenson, NJ, USA).

The frequency of $\mathrm{CD} 45^{-} \mathrm{CD} 271^{+} \mathrm{MSC}$ was calculated in relation to total live cells. The expression of CD73, CD105 and CD90 was calculated on gated $\mathrm{CD} 45^{-} \mathrm{CD} 271^{+} \mathrm{MSCs}$, isotype controls were purchased from BD Biosciences. Additionally, the same antibody panel was used on Osteocel digests (but without the addition of CountBright beads) and acquired using ImageStream ${ }^{\circledR}$ flow cytometer (Amnis, Seattle, Washington DC, USA); which allowed the simultaneous assessment of $\mathrm{CD} 45^{-} \mathrm{CD} 271^{+}$MSC morphology and phenotype.
The total number of enzymatic-released CD45 $\mathrm{CD} 271^{+}$MSCs per gram of Osteocel $(n=5)$ was determined as follows. First, the total number of MSCs in the staining volume was calculated in relation to total CountBright beads according to manufacturer's instructions and adjusted to give the total number of cells in the sample. Subsequently, this count was converted to the total number MSC per gram of tissue for each particular Osteocel sample, taking into account the weight of Osteocel bone before digestion.

\section{Analysis of MSC-related activity in Osteocel using whole genome microarray analysis}

Osteocel samples were allowed to thaw; cryoprotectant was removed and the bone chips were rinsed with $5 \mathrm{ml}$ PBS. Total RNA was isolated using a column-based extraction protocol with a DNase I step (Ambion ${ }^{\circledR} /$ Life Technologies, NE, USA); the purity and quantity of total RNA was determined using a NanoDrop ND-1000 UV spectrophotometer (NanoDrop Products, DE, USA) and the integrity of RNA was qualified using Agilent Bioanalyzer 2100 (Agilent Technologies, CA, USA). Control RNA samples of adult human osteoblast (406-R25a) and adult human dermal fibroblast (106-R25a) cell lines (Cell Applications, Inc., CA, USA) were treated similarly.

Total mRNA (100 ng per sample) was used for preparation of biotin-labeled targets using an Illumina TotalPrep ${ }^{\mathrm{TM}}$ kit (Ambion Inc., TX, USA) with one round of amplification. Biotin-labeled cRNA was used to probe HumanHT-12 v3 Expression BeadChips (Illumina, Inc., CA, USA). Hybridization, washing, and scanning of the arrays were performed according to the manufacturer's instructions. Illumina BeadScan software was used to produce data files for each array; raw data were extracted using Illumina BeadStudio software v3. Following quality assessment, data on each array were summarized into raw intensity values, gene identifiers and corresponding probe IDs. Comparison of the differential expression patterns between Osteocel samples and the control cell lines with a dataset obtained from MSCs and their progeny [30] resulted in a list of markers of particular interest based on their known functions in MSC, bone development and physiology (listed in Table 1).

\section{Analysis of Osteocel-MSC functionality following explant culture \& low passage expansion}

To confirm the identity of Osteocel-resident MSCs, flow cytometry on passage 2-3 expanded cells was performed using full ISCT antibody panel [29]; consisting of CD73-PE, CD90-PE, CD105-PE, CD14-PE, CD19FITC, CD34-PcP, CD45-PE-Cy7 and HLADR-AP- 
Table 1. Molecular analysis of Osteocel ${ }^{\circledR}$ in comparison to dermal fibroblast and osteoblast cell lines.

\begin{tabular}{|c|c|c|c|}
\hline Full name & Gene code & $\begin{array}{l}\text { Versus } \\
\text { osteoblasts }^{\dagger}\end{array}$ & $\begin{array}{l}\text { Versus } \\
\text { fibroblasts }^{\dagger}\end{array}$ \\
\hline Osteopontin, transcript variant 2 & SPP1 & 22.3 & 119.7 \\
\hline Osteopontin, transcript variant 1 & SPP1 & 26.0 & 64.2 \\
\hline Chemokine (C-X-C motif) receptor 7, transcript variant 1 & CXCL7 & 29.4 & 63.3 \\
\hline S100 calcium binding protein A8 & S100A8 & 88.3 & 62.8 \\
\hline Transferrin & $T F$ & 30.8 & 54.3 \\
\hline Insulin-like growth factor binding protein 3, transcript variant 1 & IGFBP3 & 1.5 & 38.1 \\
\hline Bone $\gamma$-carboxyglutamate (gla) protein (osteocalcin) & $B G L A P$ & 26.6 & 36.8 \\
\hline Vascular cell adhesion molecule 1, transcript variant 1 & VCAM1 & 7.8 & 25.9 \\
\hline S100 calcium binding protein A12 & S100A12 & 16.3 & 22.4 \\
\hline $\begin{array}{l}\text { Chemokine (C-X-C motif) ligand } 12 \text { (stromal cell-derived factor } 1 \text { ), transcript } \\
\text { variant } 1\end{array}$ & CXCL12 & -3.3 & 21.2 \\
\hline Frizzled-related protein & $F R Z B$ & 15.4 & 17.00 \\
\hline S100 calcium binding protein A9 & S100A9 & 125.0 & 16.2 \\
\hline Bone morphogenetic protein 2 & $B M P 2$ & 22.5 & 12.4 \\
\hline Integrin-binding sialoprotein (bone sialoprotein, bone sialoprotein II) & IBSP & 9.0 & 12.3 \\
\hline Alkaline phosphatase, liver/bone/kidney & $A L P$ & 2.0 & 11.9 \\
\hline Distal-less homeobox 5 & $D L X 5$ & 3.8 & 11.2 \\
\hline Homo sapiens parathyroid hormone receptor 1 & PTHR1 & 7.7 & 8.3 \\
\hline Bone morphogenetic protein 6 & BMP6 & 13.2 & 5.5 \\
\hline Homo sapiens jagged 1 (Alagille syndrome) & JAG1 & -1.9 & 5.2 \\
\hline Homo sapiens gap junction protein, alpha 1, 43 kDa (connexin 43) & GJA1 & 2.8 & 4.6 \\
\hline Runt-related transcription factor 2, transcript variant 1 & $R \cup N X 2$ & 2.0 & 2.2 \\
\hline Sp7 transcription factor, osterix & SP7 & 2.1 & 2.1 \\
\hline Distal-less homeobox 3 & $D L X 3$ & 1.9 & 2.0 \\
\hline Gremlin 1, cysteine knot superfamily, homolog (Xenopus laevis) & GREM1 & -10.5 & -3.8 \\
\hline
\end{tabular}

C-H7 (all antibodies from BD Biosciences) with 4',6-diamidino-2-phenylindole (DAPI) as a viability marker [31]. To confirm MSC functionality, mesenchymal tri-lineage differentiation assays were performed in standard conditions as previously described [27].

The immunosuppressive capacity of Osteocel-MSCs was tested in co-culture with $\mathrm{CD}^{+}{ }^{+} \mathrm{T}$ cell responders (Tresp). Tresp were purified from peripheral blood mononuclear cells by depletion of non-CD $4^{+}$cells $\left(\mathrm{CD}^{+} \mathrm{T}\right.$ cell isolation kit II, Miltenyi Biotec) and labeled with the carbocyfluorescein succinimidyl ester dye analogue, CellTrace ${ }^{\mathrm{TM}}$ Violet (Invitrogen), in order to track Tresp cell divisions following stimulation. Tresp proliferation was stimulated using MSC Suppression Inspector containing Anti-Biotin MACSiBead ${ }^{\mathrm{TM}}$ particles preloaded with biotinylated CD2, CD3, and CD28 antibodies (Miltenyi Biotec). Prior to co-culture, p2 Osteocel-MSCs were irradiated (30 Gy) to prevent further proliferation in co-culture with Tresp. Co-cultures were established in flat-bottomed 96-well plates using the following MSC:Tresp ratios: 1:1, 1:2, 1:4 and 1:8 [32]. The total number of Tresp/well was kept constant $\left(10^{5} /\right.$ well $)$, and the number of MSCs was adjusted according to specific MSC:Tresp ratios. Control wells included: labeled but not stimulated Tresp (no stimulation control) and labeled+stimulated Tresp without MSCs (No MSC control) [32]. Co-cultures were maintained in Glutamax ${ }^{\mathrm{TM}}$ RPMI 1640 (Invitrogen) supplemented with $10 \%$ human AB serum (Sigma, Dorset, UK) for 5 days.

The inhibition of Tresp proliferation under the influence of MSCs was measured using flow cytometry by analyzing the pattern of CellTrace Violet dilution on Tresp cells [33]. For accurate gating on Tresp cells, CD90-FITC (Serotec) and CD45-PE-Cy7 (BD Biosciences) were used to exclude potential contamination 
with MSCs; 7-AAD was used as a viability marker. Tresp divisions/generations were calculated using ModFit software version 3.2 (Verity Software House, Topsham, ME. USA). MSC suppression was calculated using relative division index as previously described [34]; and calculated as an 'average' Tresp generation (calculated as a geometric mean) in MSC-containing wells and normalized to the 'average' Tresp generation in no MSC control (100\%) [34].

\section{Processing \& analysis of control samples IC bone \& BM aspirate}

IC bone fragments were washed in PBS, weighed and treated with collagenase to remove the cells, as described for Osteocel samples (above); the $\mathrm{CD} 45^{\circ} \mathrm{CD} 271^{+}$MSC abundance per gram of bone was calculated similarly. The remaining untreated IC bone fragments were used for histology and ESEM microscopy. MSC enumeration in BM aspirates was performed as previously described [35]. Briefly, $50 \mu \mathrm{l}$ of BM aspirate was incubated with CD45-PE-Cy7, CD73-PE and CD271-APC. Erythrocytes were lysed using $2 \mathrm{ml}$ ammonium chloride solution (168 mM $\mathrm{NH}_{2} \mathrm{Cl}_{2}, 10 \mathrm{mM} \mathrm{KHCO}$ and $1 \mathrm{mM} \mathrm{EDTA}$ ) containing $0.5 \mu \mathrm{g} / \mathrm{ml}$ DAPI (Sigma). Similar to OsteocelMSC absolute counting protocol, counting beads were added to allow absolute MSC quantification per one $\mathrm{ml}$ of aspirate. Data were collected using LSRII and analyzed using FACSDiva software version 7.

\section{Statistical analysis}

The Mann-Whitney nonparametric test was used to compare MSC frequencies and their absolute numbers in Day 0 Osteocel, control IC bone and BM aspirate. Statistical significance was defined as $\mathrm{p}<0.05$. All statistics were calculated using SPSS $^{\circledR}$ Version 21.

\section{Results}

\section{Cellular allograft contains functionally competent MSCs}

Our first aim was to confirm and extend previous findings [20,21] indicating MSC 'outgrowth' in Osteocel explant cultures. Consistent with previous findings, we observed plastic-adherent, spindle-shaped cells emanating from Osteocel fragments that were capable of further expansion with good preservation of their fibroblastic morphology (Figure 1A). Osteocel-derived cultures fulfilled the minimal criteria for MSCs as defined functionally (Figure 1B) and phenotypically (Figure 1C) [29]. This was evident by the uniform positivity of Osteocel-derived cultures for MSC markers CD73, CD90 and CD105, and the lack of expression for hematopoietic-lineage markers such as CD45, CD19 and CD14.
Immunomodulation capacity has emerged as an important clinically relevant feature of MSCs [32]. We used multiparameter flow cytometry to accurately identify Tresp in co-cultures with different amounts of p2 Osteocel-MSCs (Figure 1D) and observed robust inhibition of Tresp proliferation (Figure 1E). In the absence of MSCs, MACSiBead-stimulated Tresp cells have undergone on average eight divisions in 5 days; this was inhibited to a maximum of three divisions at MSC:Tresp ratio of 1:1 (Figure 1E). This inhibitory effect was MSC dose-dependent, that is, increased with increasing numbers of MSCs/well (from ratios $1: 8$ to $1: 1$ ) (Figure $1 \mathrm{~F}$ ).

Altogether these data confirmed the outgrowth of MSCs from Osteocel explant cultures, indicating the presence of viable culture-initiating MSCs in the original bone fragments. Furthermore, these experiments showed, for the first time, strong immunosuppressive capacity of Osteocel-MSCs.

\section{Cellular allograft displays MSC- \& osteoblast-} related signaling activity by microarray analysis Since the immune cell component (lymphocytes and myelomonocytic lineage cells) is removed from Osteocel cancellous bone by selective washes, any viable cells remaining associated with the allograft could be predicted to represent stromal lineage cells strongly attached to or embedded in bone. These could encompass MSCs, osteoprogenitors, preosteoblasts and osteoblasts, osteocytes, preadipocytes/mature adipocytes, as well as bone-resorbing osteoclasts. To detect any steady-state MSC-related signaling activity occurring in Osteocel, we used whole human genome array technology and compared gene expression in Osteocel lyzates with control osteoblast and fibroblast cell lines (latter used as negative controls for MSCs) [36]. Analysis revealed over 23 osteogenic and MSC-related genes that were differentially expressed by the Osteocel samples at a level that was considered significant (greater-than or less-than a twofold change) [36]; the results are summarized in Table 1.

Many of the osteogenic genes were up-regulated, including those encoding osterix, osteocalcin, osteopontin, CXCL12 and bone/liver/kidney alkaline phosphatase, which were previously described by us and others as highly-specific for uncultured BM MSCs [36-38]. IGFPB3 was approximately 30-fold higher in Osteocel cell lyzates compared with dermal fibroblasts, parallel to our previous data using MSCs [36]. Similar trends were found for $F R Z B /$ soluble frizzledrelated protein 3, connexin 43 and jagged 1, all highly specific for uncultured MSCs [36,37], with other evidence indicating their expression in preosteoblasts [39] or bone-lining cells [40]. 


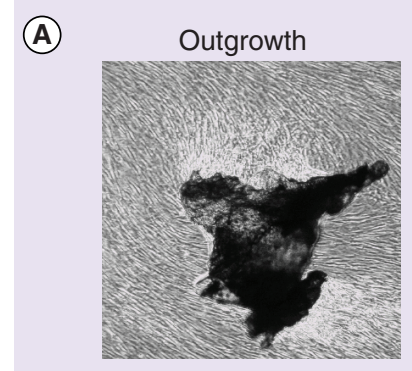

(c)

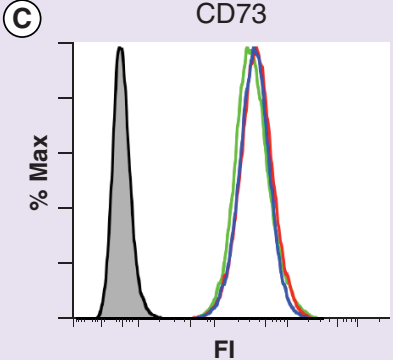

(D)

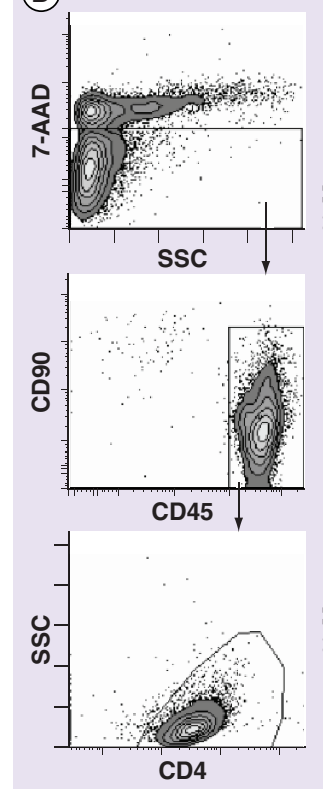

(E)
(B) Chondrogenesis

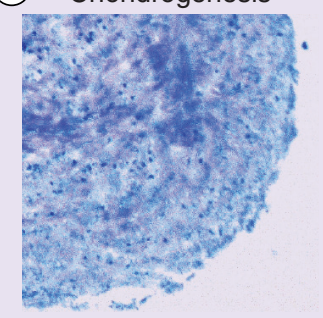

CD90

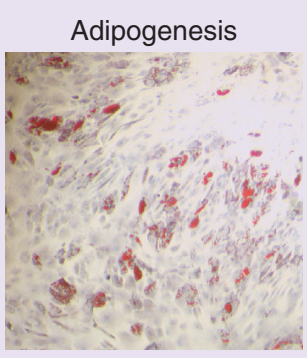

CD105

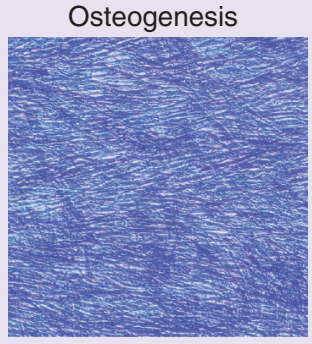

CD45

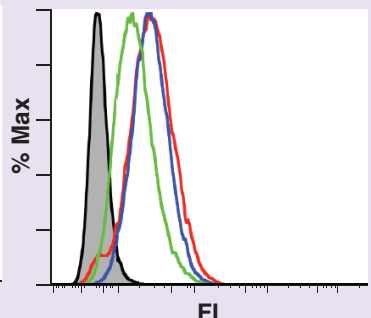

FI

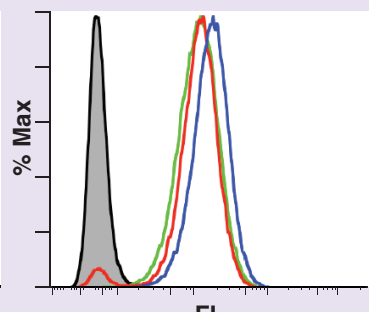

FI

FI
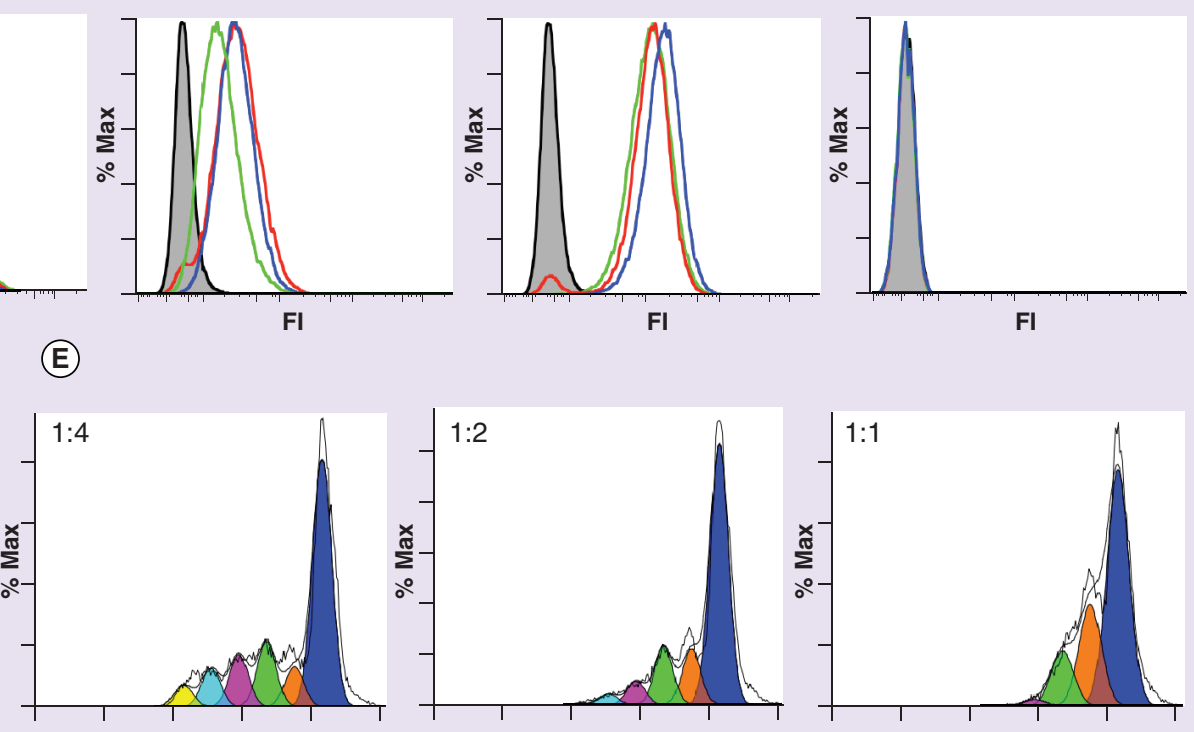

FI

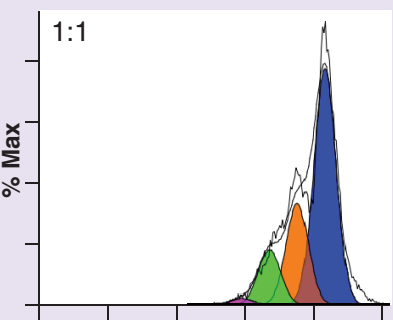

FI

(F)
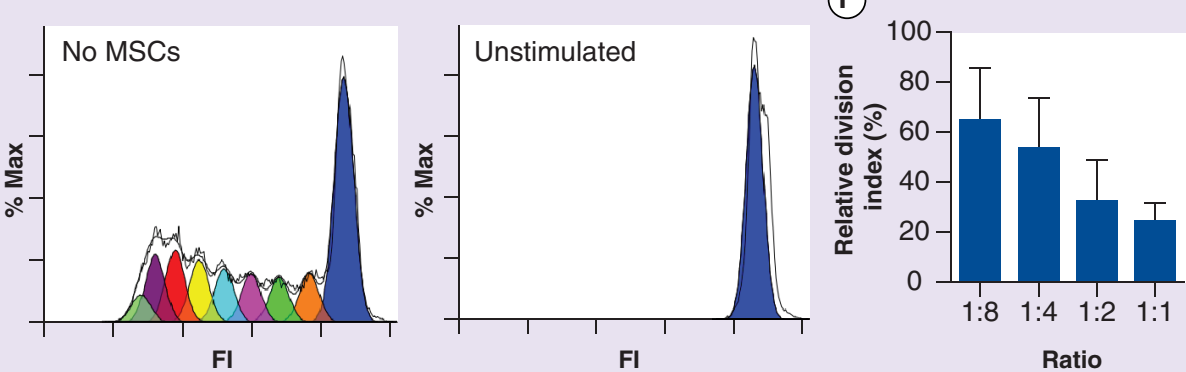

Figure 1. Phenotypic and functional characterization of cells grown from Osteoce ${ }^{\circledR}$ explant cultures.

(A) Proliferative and (B) differentiation capacities, chondrogenesis and adipogenesis were assessed on day 21 post-induction by Toluidine Blue or Oil Red-O staining, respectively. Osteogenesis was assessed by alkaline phosphatase staining on day 14 post-induction; original magnification of microphotographs $\times 100$ and $\times 40$ for chondrogenesis. (C) Phenotypic characterization of Osteocel-derived cells confirming their identity as MSCs ( $n=3$ Osteocel lots). Gray filled histograms indicate isotype control staining. (D-F) Immunosuppressive capacity of Osteocel-MSCs in co-culture with T cell responders (Tresp) CD4+ T cells. (D) Gating strategy for Tresp cell employing initial gating for live cells followed by exclusion of MSCs and final gating on the CD4+ population. (E) Histograms indicating proliferation patterns of Tresp co-cultured at ratios 1:1 to 1:4 with MSCs (a representative donor, colors represent cell doublings). (F) Inhibition of Tresp proliferation measured as relative division index normalized to no MSC control ( $n=4$ Osteocel lots, 1:1 to 1:8 ratios). Error bars represent SD.

FI: Fluorescence intensity; MSC: Multipotential stromal cell; SSC: Side scatter.

GREM1, an inhibitor of BMP signaling [41,42] was expressed at a lower level in Osteocel than either osteoblasts or fibroblasts; potentially allowing for increased osteoinductive BMP signaling. The gene expression of BMP2 was also 22.5- and 12.4-fold higher in Osteocel lyzates compared with both osteoblasts and fibroblasts, respectively (Table 1). Altogether, these data revealed strong MSC- and osteoblast-related signaling 
activity in Osteocel indicating steady-state functionality (at the transcriptional level) of these cells in situ.

\section{Cellular allograft contains viable bone-lining cells \& osteocytes}

We next performed microscopic analysis to investigate the potential location of MSCs resident in Osteocel. The depletion of hematopoietic BM was clearly evident on histological sections of Osteocel (Figure 2A) compared with control IC bone (Figure 2B). In Osteocel, cell presence was detected in bone lacuni (osteocytes, Figure 2A, white filled arrows) and within bone pores (Figure 2A, black filled arrows). Bone-lining cells and a stromal cellular network was preserved in many fragments studied (Figure 2A, black filled arrows).

Confocal microscopy revealed the existence of live (as well as some dead) cells on Osteocel surface, which were primarily located in bone crevices (Figure 2C); this was consistent with histology data (Figure 2A). Digital removal of bone surface's reflected light indicated the presence of more live cells underneath the bone surface, suggesting that osteocytes were also viable (Figure 2D). High numbers of osteocytes connected with cananiculi could also be seen by inverted light microscopy (Figure 2E), with cananiculi clearly visible at higher magnifications (Figure 2F, white filled arrows).

Because osteocytes are strongly embedded in bone matrix, we reasoned that only the bone-lining compartment could harbor MSCs giving rise to Osteocel outgrowth cultures. We next used ESEM and compared the abundance of stromal cells on Osteocel with that of age-matched IC bone (Figure 3, top panels). Day 0 Osteocel fragments were notably less cellular than control bone. This was expected, as a consequence of Osteocel's immunodepletion processing procedure to remove the hematopoietic lineage cells [21] and consistent with histology data (Figure 2A \& B).

We next explored in situ cell growth and colonization of Osteocel and control bone by incubating fragments in culture for 21 days prior to ESEM imaging (Figure 3, middle and bottom panels). On day 21 of culture, stromal cell layers bridging the bone pores were observed in both Osteocel and control bone (Figure 3, middle panels). These cells occupied empty spaces within bone pores and were anchored to the bone via clearly visible attachment points (Figure 3, bottom panels).

Altogether our microscopy study indicated the presence of viable osteocytes and bone-lining cells in Osteocel; furthermore, bone-lining cells (or a fraction of) were able to proliferate in situ prior to their egress onto the plastic and subsequent formation of $2 \mathrm{D}$ explant cultures. This established a potential topography of Osteocel-MSCs near to, or at the bone surface. This was in agreement with previous publications show-
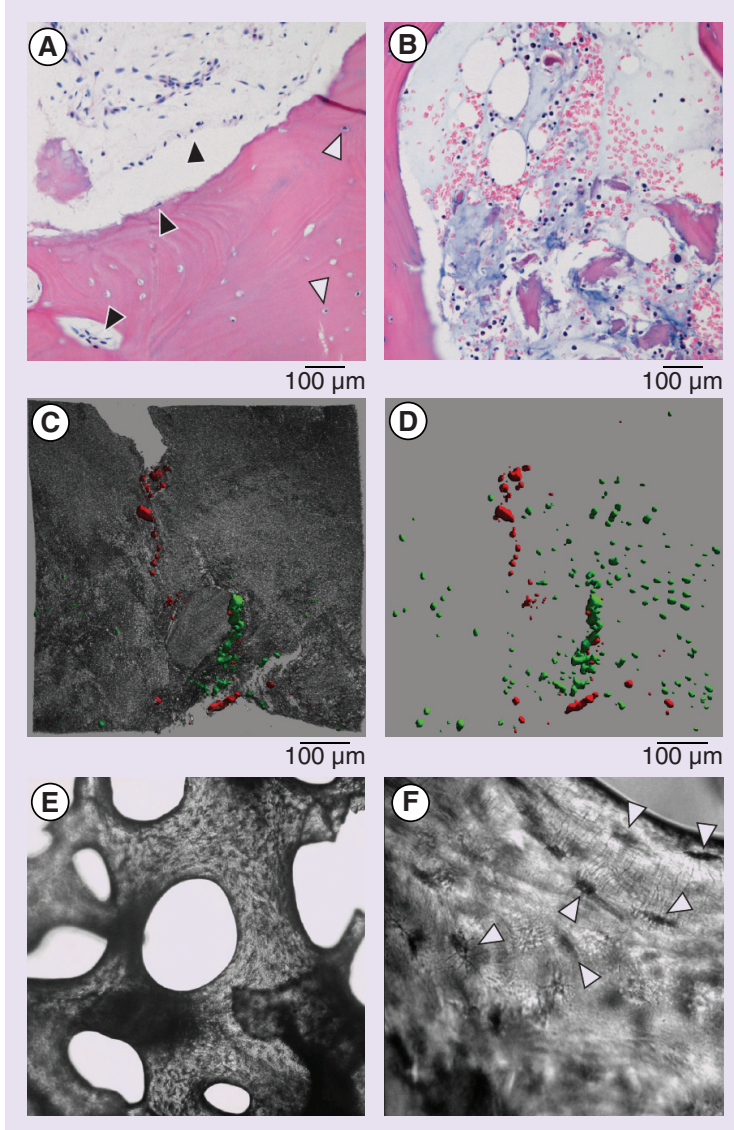

Figure 2. Assessment of cell abundance in Osteocel ${ }^{\circledR}$ as analyzed by histology, confocal microscopy and light microscopy. (A) Hematoxylin and eosin staining of decalcified fragments of Osteocel bone; compared with (B) control iliac crest bone; black filled arrows indicate presence of bone-lining cells, white filled arrows indicate embedded octeocytes. (C) Confocal microscopy indicating the presence of live (green) and dead (red) cells on the surface of Osteocel and (D) following the removal of bone reflected light signal showing more live cells embedded in the bone matrix (osteocytes), similar to (A). (E) Abundant osteocytes stained with Crystal Violet, original magnification $\times 40$ and $(F) \times 100$ indicated by white filled arrows.

ing the bone-lining (in addition to their perivascular) topography of MSCs in human bone [28,38].

\section{Cellular allograft contains increased proportions \& large numbers of viable CD45-CD271+ MSCs}

The next set of experiments was designed to identify and quantify Osteocel-MSCs following their enzymatic release from the bone surface (i.e., prior to any cell culture) using flow cytometry. For this, we first refined the flow cytometry method for enumeration of $\mathrm{CD} 45^{-} \mathrm{CD} 271^{+}$MSCs in bone digests using fragments of femoral head bone (these sample are more readily available compared with IC bone at our hospital). 


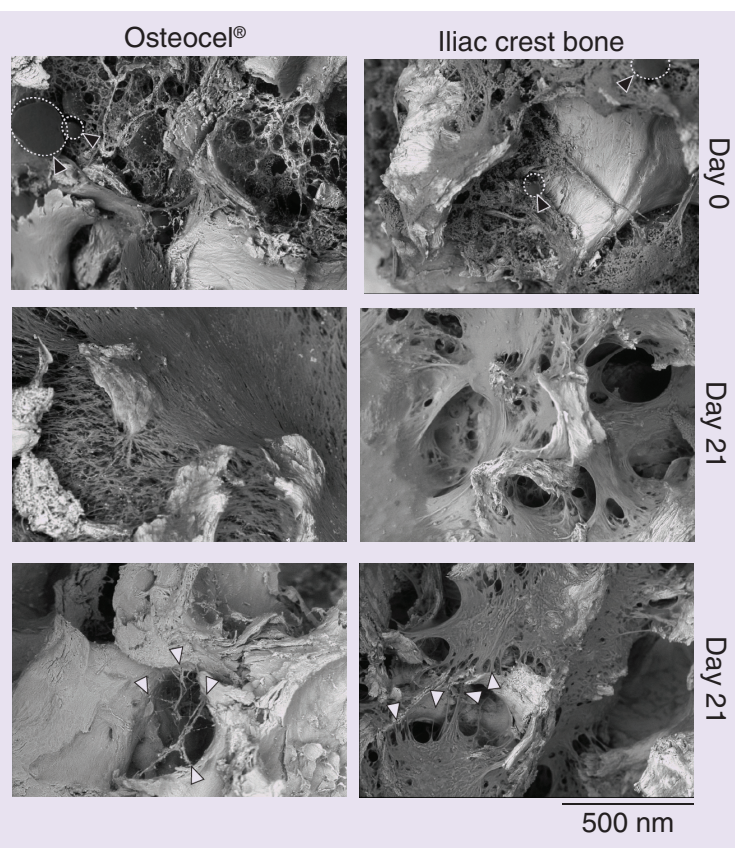

Figure 3. Environmental scanning electron microscopy of stromal cell abundance (Day 0, top panels) and in vitro scaffold colonization (Day 21, middle and bottom panels) in Osteoce ${ }^{\oplus}$ and control iliac crest bone. White filled arrows show cell attachment points to bone, fat cells are indicated by dotted outline and black filled arrows.

This was required because, specific for bone digests, we needed to account for small bone debris (absent in BM aspirates), which are auto-flourescent, giving false-positive results. Since bone debris do not contain a nucleus/DNA, they could not be easily eliminated using common DNA-based live/dead discriminatory dyes (7-AAD or DAPI) and, thus, could appear falsely as live cells. For the analysis of Osteocel, the exclusion of this debris was even more pertinent, as small DBM particles not removed by sieving could lead to incorrect estimation of MSC viability and phenotype. We therefore used a new-generation of live/dead cell discrimination dyes that are based on a cell's metabolic activity and compared staining with a standard gating method based on 7-AAD (Figure 4). Our new method clearly resolved live cells from bone debris (Figure 4A), which were otherwise included in the live gate of the conventional staining (Figure 4B).

When the refined flow cytometry method was applied to Osteocel $(\mathrm{n}=9)$; a clear population of $\mathrm{CD} 45^{-} \mathrm{CD} 271^{+}$ MSCs was evident with an average frequency of $30.4 \%$ (Figure 5A, left panel). These cells were also positive for CD73 (right panel), as well as CD90 and CD105 (Figure 5C), consistent with their identity as MSCs $[27,29,43]$. The percentage of $\mathrm{CD} 45^{+} \mathrm{CD} 271^{-}$hematopoietic-lineage cells (HLCs) was very low (5.6\%, range 3.1-9.1\%) (Figure 5A, left panel).
In control age-matched IC bone samples $(\mathrm{n}=6)$, $\mathrm{CD} 45^{\circ} \mathrm{CD} 271^{+}$MSC frequency was an average $0.3 \%$, significantly lower compared with Osteocel with an average $30.4 \%$ (Figure 5B, left panel). Similar to CD $455^{-} \mathrm{CD} 271^{+}$MSCs in Osteocel, IC bone-MSCs were also positive for $\mathrm{CD} 73, \mathrm{CD} 90$ and $\mathrm{CD} 105$ (Figure $5 \mathrm{C}$ ). The percentage of $\mathrm{CD} 45^{+} \mathrm{CD} 271^{-}$HLCs in IC bone was on average 93\% (range 89-95\%) (Figure 5B, left panel). The CD $455^{-} \mathrm{CD} 271^{+}$MSC purity in Osteocel was therefore an average 101-fold $(p<0.001)$ higher than in age-matched IC bone. Furthermore, an average ratio of MSCs to HLCs was 6:1 in Osteocel (MSC predominant), whereas in IC control bone, it was approximately 1:370 (HLC predominant). This clearly demonstrated the effective removal of HLCs ( 2200-fold decrease) from Osteocel, and retention of the native MSC population.

ImageStream analysis of Osteocel digests confirmed viable cell morphology of $\mathrm{CD} 45^{\circ} \mathrm{CD} 271^{+}$ events recovered from the 'live-cell' gate, as well as their CD73-positivity (Figure 5D, top panel). Conversely, events recovered from the 'dead cells/debris' region consisted of misshaped DBM or bone debris particles (Figure 5D, bottom panel).

Finally, we compared the total number of CD 45 ${ }^{\circ}$ D271 $21^{+}$MSCs per gram of Osteocel bone with that of age-matched IC bone (Figure 5E). In control bone, a median of 1.3 million of $\mathrm{CD} 45^{-} \mathrm{CD} 271^{+}$ MSCs/g were present, consistent with previous estimations [27]; in Osteocel this number was 0.53 million/g (difference not statistically significant).

BM aspirates are commonly used to 'load' synthetic scaffolds with MSCs to enhance graft osteoinductivity [11-13]. The final set of experiments was designed to compare $\mathrm{CD} 45^{\circ} \mathrm{CD} 271^{+}$MSC abundance in $1 \mathrm{~g}$ of Osteocel with one $\mathrm{ml}$ of age-matched BM aspirate (Figure 5E). For this, we employed our previously-validated, single-platform flow cytometry method to measure $\mathrm{CD} 45^{-} \mathrm{CD} 271^{+}$MSCs in $\mathrm{BM}$ aspirates [35]. Total numbers of $\mathrm{CD} 45^{-} \mathrm{CD} 271^{+} \mathrm{MSCs} / \mathrm{ml}$ of BM aspirate were a median of $12,000 / \mathrm{ml}$ (range 1126-28,210). Considering that approximately $530,000 \mathrm{CD} 45^{-\mathrm{CD}} 271^{+}$MSCs were present in $1 \mathrm{~g}$ of Osteocel, this would be equivalent to approximately $45 \mathrm{ml}$ of good-quality, undiluted BM aspirate.

In summary, these flow cytometry results showed that similar to autograft IC bone, Osteocel fragments contained a clear population of viable $\mathrm{CD} 45^{-} \mathrm{CD} 271^{+} \mathrm{CD} 73^{+} \mathrm{CD} 90^{+} \mathrm{CD} 105^{+}$MSCs. MSCs were found in Osteocel and IC bone at approximately $0.5-1.3$ million/g (based on median values), however Osteocel-MSCs were much purer (due to effective removal of HLCs). 


\section{Discussion}

Although autologous bone graft remains the most used graft material in orthopedic surgery, it has significant limitations related to yield and harvesting techniques [15]. The clinical use of synthetic bone substitutes alone or loaded with BM aspirate [11-13] remains limited due to lack of level-one evidence and cost/benefit implications [15,44]. Despite being available in different formulations [45], the use of traditional bone allografts on the other hand, has been limited due to known lack of osteogenic cells $[15,45]$. In this study we investigated a viable cellular bone allograft material Osteocel, which has shown successful clinical outcomes [16,18-20,46-51], for the presence of MSCs, alongside the 'gold standard' autograft IC bone and $\mathrm{BM}$ aspirate; this was done without any culture expansion, that is, in their clinically relevant condition. We detected MSC-specific signaling activity in Osteocel lyzates and extracted native $\mathrm{CD} 45^{-} \mathrm{CD} 271^{+}$MSCs from Osteocel bone by enzymatic digestion. Using confocal and electron microscopy we documented the presence of viable osteocytes and bone-lining cells in Osteocel, with the latter being capable of extensive proliferation in situ before their egress onto plastic. We proved the MSC nature of Osteocel-derived cultures using standard ISCT criteria and for the first time showed their strong immunoregulatory capacity in co-culture with T-cells. Altogether our data indicate that Osteocel con- tains large numbers of viable osteogenic cells such as osteocytes and MSCs. These findings underpin how viable cellular bone allografts rich in MSCs could represent an effective alternative to autograft bone in orthopedics.

Despite its widespread clinical use and the lack of reported complications, a rigorous cellular characterization study of Osteocel has been very limited [20,21]. In comparison with two previous studies, which explored Osteocel-MSCs following cultivation, our work has been specifically focused on native MSCs resident in Osteocel; this was intended to reflect 'the status' of the graft material as it would be used clinically, and to directly compare it with autograft bone. In 2010, we showed that human bone-resident MSCs had the $\mathrm{CD} 45^{-} \mathrm{CD} 271^{+}$phenotype [27]; which was later confirmed independently $[28,38]$. Having refined a flowcytometry method to eliminate bone debris/DBM from analysis, we now show that MSCs were not only viable, but also abundant in Osteocel, and their relative purity considerably exceeded that of autograft bone (101-fold). This increased purity was due to the effective depletion of immune cells/HLCs following processing ( $<6 \%$ HLCs remaining), which was in stark contrast with autograft bone and BM aspirate where HLCs are the predominant population.

In our previous study we did not observe any decline in $\mathrm{CD} 45^{-} \mathrm{CD} 271^{+} \mathrm{MSCs}$ in aged donors,

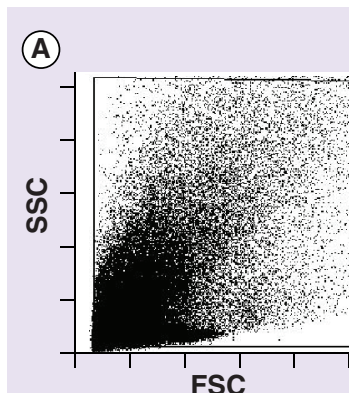

(B)
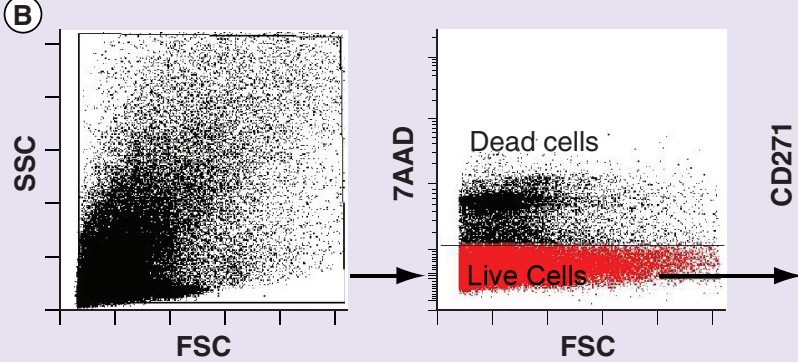

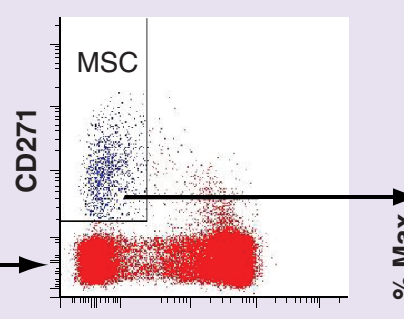

CD45

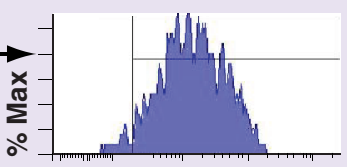

CD73

Figure 4. Analysis of CD45-CD271+ multipotential stromal cell abundance in femoral head bone digests. (A) New live/dead binding dyes compared with (B) a traditional 7-AAD-based method. Far left panels: dot plots showing size distribution of all events (cells and debris). Middle left panels: gating on live cells (shown in red). Middle right panels: identification of CD45 CD271+ MSCs (shown in blue). Far right panels: histogram of CD73 positivity on the CD45-CD271+ MSC population. Vertical lines indicate the boundary for isotype control binding, horizontal lines indicate the region used to calculate the proportions of $\mathrm{CD} 73^{+}$cells.

FSC: Forward scatter; MSC: Multipotential stromal cell; SSC: Side scatter. 
(A)

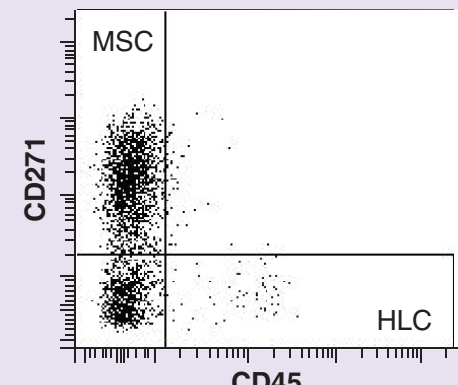

CD45

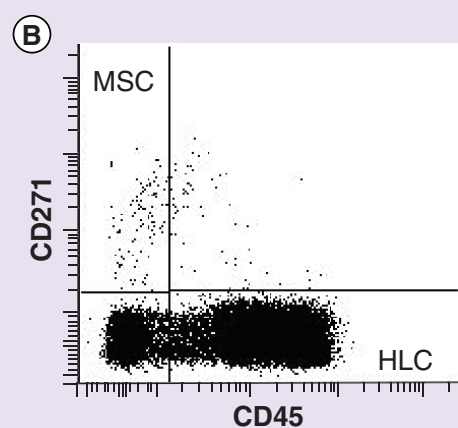

(C)

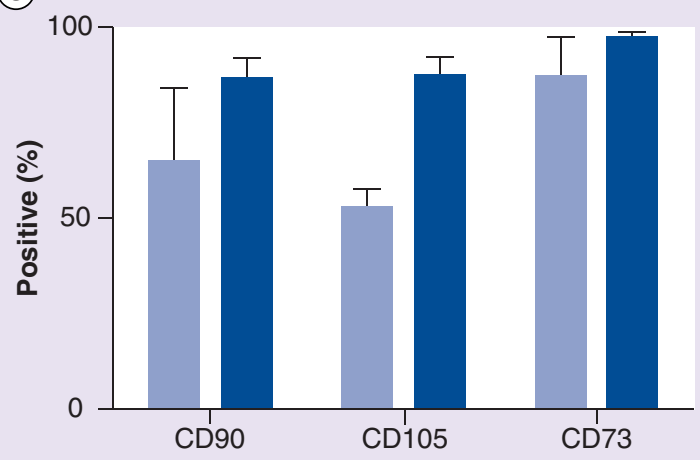

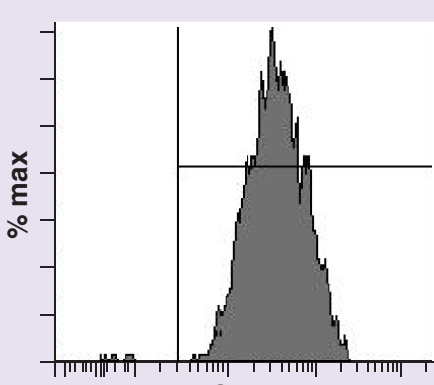

CD73

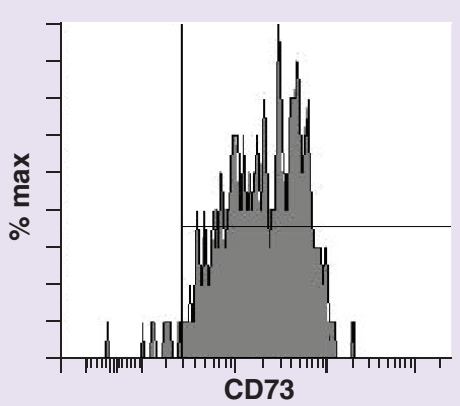

(D)

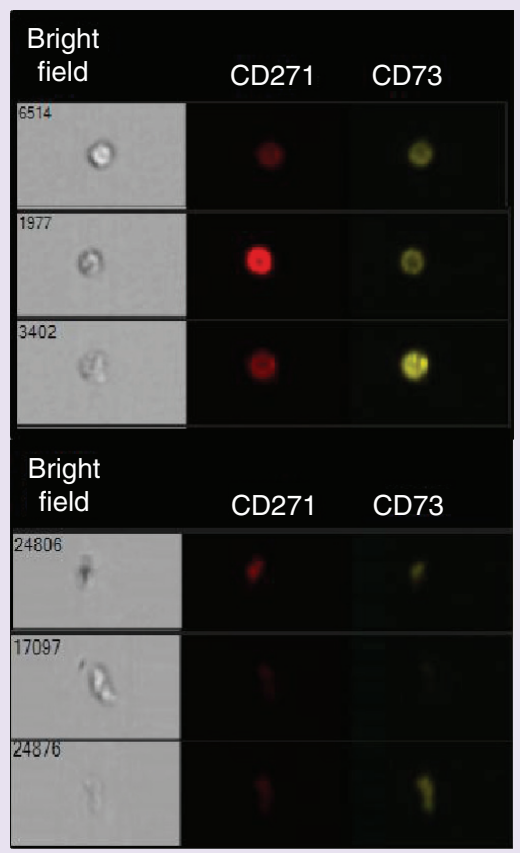

(E)

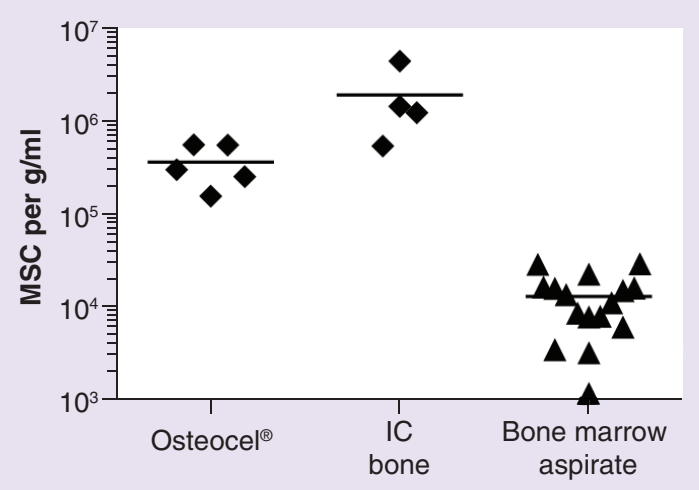

Figure 5. Analysis of CD45-CD271+ multipotential stromal cell abundance in enzymatic digests of Osteocel ${ }^{\circledR}$ and control age-matched iliac crest bone. (A) Analysis of CD45-CD271 ${ }^{+}$MSC abundance in enzymatic digests of Osteocel ${ }^{\circledR}$ and (B) control age-matched IC bone. (A \& B) Left panels show the abundance of CD $455^{-} \mathrm{CD} 271^{+}$MSCs and hematopoietic lineage cells, in (A) Osteocel and (B) IC bone, respectively. (A \& B) Middle panels show CD73 positivity of CD45-CD271+ MSCs, shown as histograms. Vertical lines indicate the boundary for isotype control binding, horizontal lines indicate a region used to calculate the proportions of CD73+ cells. (C) CD90 ( $n=8$ lots), CD105 ( $n=5$ lots) and CD73 ( $n=11$ lots) expression on CD45 CD271+ cells from Osteocel (light blue bars) compared with IC bone control (dark blue bars; $n=4$, four and five donors, respectively). (D) ImageStream ${ }^{\mathrm{TM}}$ morphological analysis of $\mathrm{CD} 45^{-} \mathrm{CD} 271^{+}$in a representative Osteocel digests collected in the 'live cell' gate (top) and debris/demineralized bone matrix gate (bottom). (E) Absolute numbers of CD45 CD271+ MSCs in Osteocel, control $\mathrm{IC}$ bone and bone marrow aspirate per $1 \mathrm{~g}$ (or $1 \mathrm{ml}$ ) indicating inferiority of bone marrow aspirate compared with both IC bone and Osteocel (both significant at $\mathrm{p}<0.0001$ ). Error bars represent standard deviation. HLC: Hemopoietic lineage cell; IC: Iliac crest; MSC: Multipotential stromal cell.

however a reduction in telomere lengths was found, potentially reflecting some MSC 'ageing' in vivo [27]. To its advantage, Osteocel is obtained from younger donors with an average age of approximately 30 years [20]. Furthermore, gene expression of Osteocel samples demonstrated the high expression of BMPs 2 and 6 and the reduction in inhibitors such Gremlin-1 [52]; this is likely to enhance the graft's osteoinductivity and be particularly beneficial for patients with co-morbidities such as diabetes [53]. The overall transcript profile of the Osteocel resembled that of osteoblasts and MSCs $[36,38,54]$ rather than fibroblasts (Table 1). Furthermore, our study showed that Osteocel also contained viable osteocytes; although these osteocytes could not be 
extracted from the mineralized tissue with collagenase, they could represent important graft constituents, since they are the mechanotransducers that modulate bone metabolism according to Wolff's Law [55,56].

The ease of BM aspirate collection and availability of concentration devices, allowing MSC enrichment five- to seven-fold [57,58], have made BM aspirate an attractive material in orthopedics [5,59-61]. Loading bone substitute scaffolds with BM aspirate is becoming common in spinal surgery in particular [11-13]. In this study we directly compared the number of MSCs in $1 \mathrm{~g}$ of cellular bone allograft with $1 \mathrm{ml}$ of BM aspirate. Our calculations reveal that even after concentration [58] the density of loaded MSCs is unlikely to match the quantity that can be delivered in $1 \mathrm{~g}$ of Osteocel and that approximately $45 \mathrm{ml}$ of carefully collected BM aspirate would be needed to achieve the same number of MSCs as present in $1 \mathrm{~g}$ of Osteocel. Harvesting these volumes of BM would require multiple needle insertion points, as shown recently [62], and may cause further discomfort and prolong recovery for the patient.

In respect to autograft IC bone, our study used enzymatic release and flow cytometry techniques to evaluate the total numbers of MSCs/gram of bone; we acknowledge, however, that this part of our study was limited by the availability of enough autograft bone that could be donated to perform the complex flowcytometry measurements. Additionally, we acknowledge that other ways of enumerating bone-resident MSCs have been employed in the past, such as bone fragmentation followed by a conventional colonyforming unit-fibroblast assay of passively-released cells [58]. However, enzymatic release has been shown to be more efficient than fragmentation/passive release [63]. Additionally, flow cytometry-based techniques are believed to be more accurate for MSC enumeration than CFU-F assay, since the latter is highly subjective and prone to under-estimating MSC numbers as a result of sub-optimal cell seeding densities or serum lots variations $[35,43,64]$.

\section{Conclusion}

In summary, we enumerated resident MSCs in IC autograft bone, BM aspirate and in a commercially available cellular bone allograft where HLCs were specifically depleted. Our data supports the osteogenic and immunoregulatory properties of viable bone allografts, which may be important in a variety of regenerative medical applications. Additionally, it complements the published clinical use of viable bone allografts in orthopedics and highlights the value of bone as an abundant source of native MSCs for a variety of regenerative medicine applications.

\section{Future perspective}

Besides its practical value to orthopedics, we believe that our work has implications for the study of native MSCs in diseased bone, particularly in areas of avascular necrosis or in BM lesions of osteoarthritis patients. For such studies, MSCs can be enzymatically extracted from patients' femoral heads, and their viability and phenotypes accurately evaluated using our novel flowcytometry technique or cell sorting. Secondly, further study of viable allografts such as Osteocel offers a technological solution to investigate the differential molecular profiles of human MSCs, proximal to bone, with that of osteocytes; so far only studied in animal models [65-67]. This could reveal novel human MSCand osteocyte-specific molecules that could be further explored as potential targets for the treatment of a systemic bone disease such as osteoporosis. Inhibition of one such osteocyte-specific molecule, Sclerostin, has been recently hailed as 'potential breakthrough in osteoporosis therapeutics' [68], and other potential candidates could follow. From a clinical perspective, future animal studies are needed to test the mechanism of action of bone-anchored MSCs in cellular allografts such as Osteocel following graft implantation, as well as any potential reactions by host immune systems [69] against Osteocel-MSCs following their differentiation to bone. For instance, whether these MSCs participate in new bone formation via their direct differentiation, similar to allogeneic MSCs loaded on ceramic scaffolds [70], or whether they serve more as immunoregulators forming a favorable niche for migration and appropriate differentiation of host MSCs remains to be established. In this context, our findings showing strong CXCL12 gene expression (gene encoding the chemokine SDF-1, involved in stem cell migration [71,72]) in this cellular allograft suggests that indeed, such cellular allografts may possess a chemotactic capacity; this should be further investigated.

\section{Acknowledgements}

The authors thank A Steiner and A Lotfy for their help with culturing Osteoce ${ }^{\circledR}$-multipotential stromal cells (MSCs) and iliac crest bone-MSCS and with differentiation and immunoregulation experiments. Additionally, they would like to acknowledge EM Erbe for the initial project planning and discussion. The authors gratefully acknowledge HB Tan for his help with consenting patients, and M Shires and J Hudson for their assistance with histology and environmental scanning electron microscopy.

\section{Financial \& competing interests disclosure}

E Jones and D McGonagle hold funding from Wellcome Trust/ EPSRC through WELMEC, a Centre of Excellence in Medical Engineering, under grant number WT 088908/Z/09/Z. TG Baboolal 
is funded by WELMEC. E Jones, D McGonagle and PV Giannoudis are also part-funded by the National Institute of Health Research via the NIHR-Leeds Musculoskeletal and Biomedical Research Unit. The consumables and reagents for this study were supported by a grant from Nuvasive Inc; E Jones, D McGonagle and PV Giannoudis were grant holders but received no salary from this grant. TA Moseley is employed at NuVasive, Inc. as the Divisional Scientist of Biologics R\&D. The authors have no other relevant affiliations or financial involvement with any organization or entity with a financial interest in or financial conflict with the subject matter or materials discussed in the manuscript apart from those disclosed.

No writing assistance was utilized in the production of this manuscript.

\section{Ethical conduct of research}

The authors state that they have obtained appropriate institutional review board approval or have followed the principles outlined in the Declaration of Helsinki for all investigations. Informed written consent has been obtained from the individuals whose samples were involved in experimental investigations.

\section{Open Access}

This article is distributed under the terms of the Creative Commons Attribution License 3.0 which permits any use, distribution, and reproduction in any medium, provided the original author(s) and the source are credited. To view a copy of the license, visit http://creativecommons.org/licenses/by/3.0/

\section{Executive summary}

- Cellular allograft contains functionally competent multipotential stromal cells and displays multipotential stromal cell- and osteoblast-related signaling activity.

- Explants generate typical multipotential stromal cell (MSC) cultures that have strong immunosuppressive capacity.

- Unmanipulated allograft displays transcriptional activity consistent with MSCs and osteoblasts.

- Microscopy reveals the presence of viable bone-lining cells and osteocytes.

- Cellular allograft contains increased proportions of viable CD45-CD271+ MSCs.

- Similar to autograft bone, Osteocel ${ }^{\oplus}$ fragments contain large numbers of CD $45-C D 271^{+}$MSCs $(\sim 0.5 \mathrm{million} / \mathrm{g})$ that are also $\mathrm{CD} 73^{+} \mathrm{CD} 90^{+} \mathrm{CD} 105^{+}$.

- The hematopoietic-lineage cells are selectively removed (>2000-fold depletion compared with autograft bone).

- A gram of Osteocel can contain MSCs equivalent to $45 \mathrm{ml}$ of bone marrow aspirate.

- Together with immunosuppressive MSCs, this underscores the successful use Osteocel, as an allograft material, in orthopedics. Overall, this material represents a 'living', natural, MSC-loaded scaffold that could intrinsically resist allogeneic reaction responses and be therefore used for broader clinical applications.

\section{References}

Papers of special note have been highlighted as:

- of interest; $\bullet$ of considerable interest

1 Marino JT, Ziran BH. Use of solid and cancellous autologous bone graft for fractures and nonunions. Orthop. Clin. North Am. 41(1), 15-26 (2010).

2 Giannoudis PV, Einhorn TA, Marsh D. Fracture heating: the diamond concept. Injury 38, S3-S6 (2007).

3 Dimitriou R, Jones E, McGonagle D, Giannoudis PV. Bone regeneration: current concepts and future directions. $B M C$ Med. 9, 66 (2011).

4 Garrison KR, Donell S, Ryder J et al. Clinical effectiveness and cost-effectiveness of bone morphogenetic proteins in the non-healing of fractures and spinal fusion: a systematic review. Health Technol. Assess. 11(30), 1-150 (2007).

5 Guerado E, Fuerstenberg CH. What bone graft substitutes should we use in post-traumatic spinal fusion? Injury 42, S64-S71 (2011).

6 Rihn JA, Kirkpatrick K, Albert TJ. Graft options in posterolateral and posterior interbody lumbar fusion. Spine 35(17), 1629-1639 (2010).
7 Carragee EJ, Hurwitz EL, Weiner BK. A critical review of recombinant human bone morphogenetic protein-2 trials in spinal surgery: emerging safety concerns and lessons learned. Spine J. 11(6), 471-491 (2011).

8 Carragee EJ, Baker RM, Benzel EC et al. A biologic without guidelines: the YODA project and the future of bone morphogenetic protein-2 research. Spine J. 12(10), 877-880 (2012).

9 Seebach C, Schultheiss J, Wilhelm K, Frank J, Henrich D. Comparison of six bone-graft substitutes regarding to cell seeding efficiency, metabolism and growth behaviour of human mesenchymal stem cells (MSC) in vitro. Injury 41(7), 731-738 (2010).

10 Evans NR, Davies EM, Dare CJ, Oreffo ROC. Tissue engineering strategies in spinal arthrodesis: the clinical imperative and challenges to clinical translation. Regen. Med. 8(1), 49-64 (2013).

- Describes regenerative medicine-based methods to repair bone defects in the spine.

11 Yamada T, Yoshii T, Sotome $S$ et al. Hybrid grafting using bone marrow aspirate combined with porous $\beta$-tricalcium phosphate and trephine bone for lumbar posterolateral spinal 
fusion: a prospective, comparative study versus local bone grafting. Spine 37(3), E174-E179 (2012).

12 Tanaka K, Takemoto M, Fujibayashi S, Neo M, Shikinami Y, Nakamura T. A bioactive and bioresorbable porous cubic composite scaffold loaded with bone marrow aspirate: a potential alternative to autogenous bone grafting. Spine 36(6), 441-447 (2011).

13 Koga A, Tokuhashi Y, Ohkawa A, Nishimura T, Takayama K, Ryu J. Effects of fibronectin on osteoinductive capability of fresh iliac bone marrow aspirate in posterolateral spinal fusion in rabbits. Spine 33(12), 1318-1323 (2008).

14 Taghavi CE, Lee K-B, Keorochana G, Tzeng S-T, Yoo $\mathrm{JH}$, Wang JC. Bone morphogenetic protein-2 and bone marrow aspirate with allograft as alternatives to autograft in instrumented revision posterolateral lumbar spinal fusion: a minimum two-year follow-up study. Spine 35(11), $1144-1150$ (2010).

15 Grabowski G, Cornett CA. Bone graft and bone graft substitutes in spine surgery: current concepts and controversies. J. Am. Acad. Orthop. Surg. 21(1), 51-60 (2013).

16 Tohmeh AG, Watson B, Tohmeh M, Zielinski XJ. Allograft cellular bone matrix in extreme lateral interbody fusion: preliminary radiographic and clinical outcomes. ScientificWorldJournal 2012, 263637 (2012).

17 Scott RT, Hyer CF. Role of cellular allograft containing mesenchymal stem cells in high-risk foot and ankle reconstructions. J. Foot Ankle Surg. 52(1), 32-35 (2013).

18 Kerr EJ 3rd, Jawahar A, Wooten T, Kay S, Cavanaugh DA, Nunley PD. The use of osteo-conductive stem-cells allograft in lumbar interbody fusion procedures: an alternative to recombinant human bone morphogenetic protein. J. Surg. Orthop. Adv. 20(3), 193-197 (2011).

19 Hollawell SM. Allograft cellular bone matrix as an alternative to autograft in hindfoot and ankle fusion procedures. J. Foot Ankle Surg. 51(2), 222-225 (2012).

20 Gonshor A, McAllister BS, Wallace SS, Prasad H. Histologic and histomorphometric evaluation of an allograft stem cell-based matrix sinus augmentation procedure. Int. J. Oral Maxillofac. Implants 26(1), 123-131 (2011).

21 Neman J, Duenas V, Kowolik CM, Hambrecht AC, Chen MY, Jandial R. Lineage mapping and characterization of the native progenitor population in cellular allograft. Spine J. 13(2), 162-174 (2013).

22 Kouroupis D, Baboolal TG, Jones E, Giannoudis PV. Native multipotential stromal cell colonization and graft expander potential of a bovine natural bone scaffold. J. Orthop. Res. 31(12), 1950-1958 (2013).

23 Jones EA, Kinsey SE, English A et al. Isolation and characterization of bone marrow multipotential mesenchymal progenitor cells. Arthritis Rheum. 46(12), 3349-3360 (2002).

24 Quirici N, Soligo D, Bossolasco P, Servida F, Lumini C, Deliliers GL. Isolation of bone marrow mesenchymal stem cells by anti-nerve growth factor receptor antibodies. Exp. Hematol. 30 (7), 783-791 (2002).

- Pioneering study showing the specificity of the CD271/ LNGFR molecule for human bone marrow (BM) multipotential stromal cells (MSCs) in vivo.

25 , Battula VL, Treml S, Schewe B, Kanz L, Vogel W. Novel markers for the prospective isolation of human MSC. In: Hematopoietic Stem Cells VI. Kanz L,Weisel KC, Dick JE, Fibbe WE (Eds). Wiley-Blackwell, NJ, USA, 262-271 (2007).

Treml S, Bareiss PM et al. Isolation of functionally distinct mesenchymal stem cell subsets using antibodies against CD56, CD271, and mesenchymal stem cell antigen-1. Haematologica 94(2), 173-184 (2009).

27 Jones E, English A, Churchman SM et al. Large-scale extraction and characterization of $\mathrm{CD} 271^{+}$multipotential stromal cells from trabecular bone in health and osteoarthritis: implications for bone regeneration strategies based on uncultured or minimally cultured multipotential stromal cells. Arthritis Rheum. 62(7), 1944-1954 (2010).

28 Rasini V, Dominici M, Kluba T et al. Mesenchymal stromal/ stem cells markers in the human bone marrow. Cytotherapy 15(3), 292-306 (2013).

29 Dominici M, Le Blanc K, Mueller I et al. Minimal criteria for defining multipotent mesenchymal stromal cells. The International Society for Cellular Therapy position statement. Cytotherapy 8(4), 315-317 (2006).

$30 \mathrm{Ng}$ F, Boucher S, Koh S et al. PDGF, TGF-beta, and FGF signaling is important for differentiation and growth of mesenchymal stem cells (MSCs): transcriptional profiling can identify markers and signaling pathways important in differentiation of MSCs into adipogenic, chondrogenic, and osteogenic lineages. Blood 112(2), 295-307 (2008).

31 Cox G, Boxall SA, Giannoudis PV et al. High abundance of CD271 $1^{+}$multipotential stromal cells (MSCs) in intramedullary cavities of long bones. Bone 50(2), 510-517 (2012).

32 Krampera M, Galipeau J, Shi Y, Tarte K, Sensebe L, Committee of the International Society for Cellular Therapy. Immunological characterization of multipotent mesenchymal stromal cells - the International Society for Cellular Therapy (ISCT) working proposal. Cytotherapy 15(9), 1054-1061 (2013).

33 Noort WA, Oerlemans MI, Rozemuller $\mathrm{H}$ et al. Human versus porcine mesenchymal stromal cells: phenotype, differentiation potential, immunomodulation and cardiac improvement after transplantation. J. Cell. Mol. Med. 16(8), 1827-1839 (2011).

34 Roederer M. Interpretation of cellular proliferation data: avoid the panglossian. Cytometry A 79A(2), 95-101 (2011).

35 Cuthbert R, Boxall SA, Tan HB, Giannoudis PV, McGonagle D, Jones E. Single-platform quality control assay to quantify multipotential stromal cells in bone marrow aspirates prior to bulk manufacture or direct therapeutic use. Cytotherapy 14(4), 431-440 (2012).

36 Churchman SM, Ponchel F, Boxall SA et al. Transcriptional profile of native $\mathrm{CD} 271^{+}$multipotential stromal cells: evidence for multiple fates, with prominent osteogenic and Wnt pathway signaling activity. Arthritis Rheum. 64(8), 2632-2643 (2012). 
37 Mendez-Ferrer S, Michurina TV, Ferraro F et al. Mesenchymal and haematopoietic stem cells form a unique bone marrow niche. Nature 466(7308), 829-834 (2010).

-. Pioneering study identifying the phenotype and transcriptional profile of native MSCs in mouse BM.

38 Tormin A, Li O, Brune JC et al. CD146 expression on primary non-hematopoietic bone marrow stem cells correlates to in situ localization. Blood 117(19), 5067-5077 (2011).

-. Describes, for the first time, the presence of CD271 MSCs in both perivascular and bone-lining locations in human BM.

39 Watkins M, Grimston SK, Norris JY et al. Osteoblast connexin 43 modulates skeletal architecture by regulating both arms of bone remodeling. Mol. Biol. Cell 22(8), 1240-1251 (2011).

40 Calvi LM, Adams GB, Weibrecht KW et al. Osteoblastic cells regulate the haematopoietic stem cell niche. Nature 425(6960), 841-846 (2003).

41 Kloen P, Lauzier D, Hamdy RC. Co-expression of BMPs and BMP-inhibitors in human fractures and non-unions. Bone 51(1), 59-68 (2012).

42 Dean DB, Watson JT, Jin Wet al. Distinct functionalities of bone morphogenetic protein antagonists during fracture healing in mice. J. Anat. 216(5), 625-630 (2010).

43 Veyrat-Masson R, Boiret-Dupre N, Rapatel C et al. Mesenchymal content of fresh bone marrow: a proposed quality control method for cell therapy. Br. J. Haematol. 139(2), 312-320 (2007).

- First study to use flow cytometry to quantify native MSCs in human BM, which highlights its major advantage over standard colony assays.

44 Lichte P, Pape HC, Pufe T, Kobbe P, Fischer H. Scaffolds for bone healing: concepts, materials and evidence. Injury $42(6)$, 569-573 (2011).

45 Delloye C, Cornu O, Druez V, Barbier O. Bone allografts - what they can offer and what they cannot. J. Bone Joint Surg. Br. 89B(5), 574-579 (2007).

46 Caputo AM, Michael KW, Chapman TM Jr et al. Clinical outcomes of extreme lateral interbody fusion in the treatment of adult degenerative scoliosis. ScientificWorldJournal 2012, 680643 (2012).

47 Ammerman JM, Libricz J, Ammerman MD. The role of Osteocel Plus as a fusion substrate in minimally invasive instrumented transforaminal lumbar interbody fusion. Clin. Neurol. Neurosurg. 115(7), 991-994 (2012).

48 Brosky TA 2nd, Menke CRD, Xenos D. Reconstruction of the first metatarsophalangeal joint following post-cheilectomy avascular necrosis of the first metatarsal head: a case report. J. Foot Ankle Surg. 48(1), 61-69 (2009).

49 Rush SM, Hamilton GA, Ackerson LM. Mesenchymal stem cell allograft in revision foot and ankle surgery: a clinical and radiographic analysis. J. Foot Ankle Surg. 48 (2), 163-169 (2009).

50 McAllister BS. Stem cell-containing allograft matrix enhances periodontal regeneration: case presentations. Int. J. Periodontics Restorative Dent. 31(2), 149-155 (2011).
51 McAllister BS, Haghighat K, Gonshor A. Histologic evaluation of a stem cell-based sinus-augmentation procedure. J. Periodontol. 80(4), 679-686 (2009).

52 Yu H-C, Wu T-C, Chen M-R, Liu S-W, Chen J-H, Lin KM-C. Mechanical stretching induces osteoprotegerin in differentiating $\mathrm{C} 2 \mathrm{C} 12$ precursor cells through noncanonical Wnt pathways. J. Bone Miner. Res. 25(5), 1128-1137 (2010).

53 Portal-Nunez S, Manassra R, Lozano D et al. Characterization of skeletal alterations in a model of prematurely aging mice. Age 35(2), 383-393 (2013).

54 Qian H, Le Blanc K, Sigvardsson M. Primary mesenchymal stem and progenitor cells from bone marrow lack expression of CD44. J. Biol. Chem. 287(31), 25795-25807 (2012).

- Comprehensive study showing major differences in transcriptional and receptor molecule profiles between native and cultured MSCs.

55 Bonewald LF. The amazing osteocyte. J. Bone Miner. Res. 26(2), 229-238 (2011).

56 Burra S, Nicolella DP, Francis WL et al. Dendritic processes of osteocytes are mechanotransducers that induce the opening of hemichannels. Proc. Natl Acad. Sci. USA 107(31), 13648-13653 (2010).

57 Dawson JI, Smith JO, Aarvold A et al. Enhancing the osteogenic efficacy of human bone marrow aspirate: concentrating osteoprogenitors using wave-assisted filtration. Cytotherapy 15(2), 242-252 (2013).

58 Homma Y, Kaneko K, Hernigou P. Supercharging allografts with mesenchymal stem cells in the operating room during hip revision. Int. Orthop. 38(10), 2033-2044 (2014).

59 Hernigou P, Poignard A, Beaujean F, Rouard H. Percutaneous autologous bone-marrow grafting for nonunions - influence of the number and concentration of progenitor cells. J. Bone Joint Surg. Am. 87A(7), 1430-1437 (2005).

- Pioneering clinical study utilizing BM aspirate injections for the treatment of bone defects.

60 Hernigou P, Poignard A, Manicom O, Mathieu G, Rouard $\mathrm{H}$. The use of percutaneous autologous bone marrow transplantation in nonunion and avascular necrosis of bone. J. Bone Joint Surg. Br. 87B(7), 896-902 (2005).

61 Kasten P, Beyen I, Egermann M et al. Instant stem cell therapy: characterization and concentration of human mesenchymal stem cells in vitro. Eur. Cell. Mater. 16, 47-55 (2008).

62 Hernigou P, Homma Y, Lachaniette CHF et al. Benefits of small volume and small syringe for bone marrow aspirations of mesenchymal stem cells. Int. Orthop. 37(11), 2279-2287 (2013).

- Clinical/experimental study describing an optimal technique for harvesting BM aspirate.

63 Sakaguchi Y, Sekiya I, Yagishita K, Ichinose S, Shinomiya K, Muneta T. Suspended cells from trabecular bone by collagenase digestion become virtually identical to mesenchymal stem cells obtained from marrow aspirates. Blood 104(9), 2728-2735 (2004). 
- The first study showing a possibility of extracting human BM MSCs using an enzymatic digestion technique.

64 Alvarez-Viejo M, Menendez-Menendez Y, Blanco-Gelaz MA et al. Quantifying mesenchymal stem cells in the mononuclear cell fraction of bone marrow samples obtained for cell therapy. Transplant. Proc. 45(1), 434-439 (2013).

65 Paic F, Igwe JC, Nori R et al. Identification of differentially expressed genes between osteoblasts and osteocytes. Bone 45(4), 682-692 (2009).

66

Flynn JM, Spusta SC, Rosen CJ, Melov S. Single cell gene expression profiling of cortical osteoblast lineage cells. Bone 53(1), 174-181 (2013).

67 Balduino A, Mello-Coelho V, Wang Z et al. Molecular signature and in vivo behavior of bone marrow endosteal and subendosteal stromal cell populations and their relevance to hematopoiesis. Exp. Cell Res. 318(19), 2427-2437 (2012).

68

Becker CB. Sclerostin inhibition for osteoporosis - a new approach. N. Engl. J. Med. 370(5), 476-477 (2014).
69 Liu H, Kemeny DM, Heng BC, Ouyang HW, Melendez AJ, Cao T. The immunogenicity and immunomodulatory function of osteogenic cells differentiated from mesenchymal stem cells. J. Immunol. 176(5), 2864-2871 (2006).

70 Arinzeh TL, Peter SJ, Archambault MP et al. Allogeneic mesenchymal stem cells regenerate bone in a critical-sized canine segmental defect. J. Bone Joint Surg. Am. 85A(10), 1927-1935 (2003).

- A pioneering preclinical study utilizing allogeneic MSCs for repairing bone.

71 Ito $\mathrm{H}$. Chemokines in mesenchymal stem cell therapy for bone repair: a novel concept of recruiting mesenchymal stem cells and the possible cell sources. Mod. Rheumatol. 21(2), 113-121 (2011).

72 Cuthbert RJ, Churchman SM, Tan HB, McGonagle D, Jones E, Giannoudis PV. Induced periosteum a complex cellular scaffold for the treatment of large bone defects. Bone 57(2), 484-492 (2013). 